\title{
Discrimination of haymilk and conventional milk via fatty acid profiles
}

\author{
Claudia L. Laguna Paredes ${ }^{1} \cdot$ Manfred Werteker $^{2} \cdot$ Birgit Rossmann $^{1} \cdot$ Julia Keplinger $^{3} \cdot$ Isabel L. Olschewski $^{3}$. \\ Matthias Schreiner ${ }^{3}$
}

Received: 4 August 2017 / Accepted: 14 February 2018 / Published online: 19 February 2018

(c) The Author(s) 2018. This article is an open access publication

\begin{abstract}
Milk produced by feeding silage-free feed has become popular in Europe. This kind of milk has recently been recognized as "traditional speciality guaranteed" by the European Union. As a consequence, an analytical discrimination of this silagefree produced milk quality has become necessary. In this study, discrimination of "haymilk" (HM) from conventional milk $(\mathrm{CM})$ in retail samples was attempted taking in consideration all feeding seasons. For analytical discrimination, a partial least square discriminant analysis (PLS-DA) to fatty acids methyl esters (FAMEs) obtained from analysis by gas chromatography was applied. All groups of long-chain fatty acids, including saturated, odd chain fatty acids, mono- and polyunsaturated fatty acids of both cis/trans configuration, contributed to discrimination of the two types of milk, where alpha linolenic acid (+37\% in $\mathrm{HM})$ and conjugated linoleic acid (C18:2c9t11- +22\% in $\mathrm{HM})$ were the most relevant for calibration. Applying PLS-DA was successful in discriminating CM and HM from retail milk in all seasons. From 48 identified fatty acids, 18 showed different levels in CM and HM samples and could be used for discrimination of the two groups. The method was able to discriminate HM and CM produced in the cold season, but showed unclear results in the warm season due to a higher scattering of both groups. These higher deviations were attributed to the fact that most dairy cows are able to consume fresh grass during summer. Although it is not possible to discriminate HM and CM produced in warm season, the fatty acid pattern of HM can be taken as a reference, from which a properly produced HM should not deviate. A separate calibration for each season is recommended for optimal results.
\end{abstract}

Keywords Hay milk $\cdot$ Conventional milk $\cdot$ Silage $\cdot$ Fatty acids $\cdot$ Discriminant analysis $\cdot$ Gas chromatography

Electronic supplementary material The online version of this article (https://doi.org/10.1007/s11694-018-9753-0) contains supplementary material, which is available to authorized users.

Matthias Schreiner

matthias.schreiner@boku.ac.at

1 Institute for Food Safety Vienna, AGES Austrian Agency for Health and Food Safety, Spargelfeldstrasse 191, 1220 Vienna, Austria

2 Institute for Feed and Animal Nutrition, AGES Austrian Agency for Health and Food Safety, Spargelfeldstrasse 191, 1220 Vienna, Austria

3 Institute of Food Science, BOKU University of Natural Resources and Life Sciences, Muthgasse 18, 1190 Vienna, Austria

\section{Introduction}

Hard cheese from raw milk has been produced in the Alpine region for centuries. When silage feeding of dairy cows became standard in the late eighteenth century, problems with high spore counts of clostridia occurred in matured hard cheese. As a consequence, regulations regarding milk produced by feeding dairy cows without silage were implemented by the Austrian dairy farming body [1]. This "silage free" milk labeled as "haymilk" (HM) is also very popular milk for daily consumption. Haymilk hast a distinct herb aroma [2-4], which results from seasonal feeding, hay in winter period and mainly fresh grass, leguminous plants and foliage in green feeding period (summer period). The term "Haymilk" has been registered as "traditional speciality guaranteed" (TSG) by the European Union and has to fulfill strict criteria in production. For example, a selection of permitted crops is listed on the regulation and silage is of course strictly forbidden $[1,5]$. 
Compared to silage feed, hay or fresh grass induces elevated concentrations of long chain polyunsaturated fatty acids (PUFA) and a decrease of short and medium chain fatty acids as confirmed by Bugaud et al. [6]. In a recent study Roda et al. [7] confirmed that grazing cows, specifically at high altitude, have a fat profile with higher content of PUFA. In ruminants, the relation of feed fatty acids (FA) to those FAs found in milk is more complex than in monogastric animals, since ruminal bio hydrogenation adds another factor that modifies dietary FAs. Nevertheless, fatty acid patterns in milk fat reflect the respective diet to a degree that permits distinction between different feeding regimes.

Information about the impact of dietary FAs on milk is well described in the literature. Administration of high energy feed (sunflower or soy bean supplements) or other fatty supplements such as oil seeds (e.g. linseed oil), algae or fish oil, does not affect milk yield but has an influence on the composition of FAs [7-18]. These kinds of diets increase monounsaturated fatty acids (MUFAs) and PUFAs, such as alpha-linolenic acid (C18:3c9,12,15, ALA) as well as other unsaturated FAs, which are substrates for microbial hydrogenation in the rumen and are converted to a variety of unsaturated FAs, such as vaccenic acid (C18:1t11) or rumenic acid (C18:2c9,t11) [8, 10-12, 19]. A concomitant reduction of short and medium chained FAs (C10-C16) has been reported as well [20,21], but in case of palm oil supplementation, concentration of C16:0 increases [21].

In the Alpine region, seasonal changes in feeding add another factor to FA profiles that needs to be considered. In the warm season, fresh green feed (fresh grass, foliage and leguminous plants) dominates, whereas in the cold season hay is the dominant feed [4]. This feeding results also in an increase of PUFA including CLA, as confirmed in different studies [9, 22-26]. All these characteristics were extensively studied in raw milk or in feed monitored works [13, 14, 27]. For production of conventional milk (CM), there are no feeding restrictions with 8regards to fresh grass so that it may also be produced by feeding non-silage feed, which is quite common during the warm period. This fact may cause difficulties for analytical discrimination of CM and HM.

Silage fodder, which is commonly used to produce CM, contains high levels of fermentable carbohydrates and low dietary fiber (e.g. corn silage, sesame meal) and is associated with increased milk yield, milk fat and milk protein concentrations, and with benefits such as increase of digestibility, more stable ruminal $\mathrm{pH}$, and decreased risk of acidosis [28], but not with specific changes in the FAs profile of the microbial flora of the rumen. Recently it was shown that cyclopropane fatty acids, which occur in milk fat as minor component, can be used as markers for silage feeding [29] and an enzymatic hydrolyzation provoke reduction of short and medium fatty acids and increase of long fatty acids which could produce differences in the physical proprieties of FA profiles [30].

An actual study about discrimination of $\mathrm{HM}$ versus $\mathrm{CM}$ in raw milk samples was published by Werteker et al. [31], who evaluated samples directly from farms. All samples were produced in winter season to avoid effects of comparable feeding regimes of cows in summer period. The results of the study indicated that total FAs profiles from a GC-FID based methodology are a sufficient basis to differentiate HM and $\mathrm{CM}$ by multivariate data treatment.

Aim of the present study was proof, if the method is suitable for the differentiation of milk samples bought from retailers. These samples embraced milk from different seasons and from different agricultural producers, which was also processed by different dairies from all relevant regions of Austria. Taking into account that HM should contain only silage free milk and that in $\mathrm{CM}$ it is possible to introduce silage milk or silage free milk, the food authorities could use this method for quality control purposes.

\section{Material and methodology}

\section{Sampling}

A total of 84 milk samples, all of ESL (extended shelf life) quality, were obtained from five Austrian retailers, 40 samples of CM, milk potentially produced by feed containing silage, which at least did not have the hay milk label and 44 samples of HM produced by feeding silage-free feed as defined by the regulations of TSG [1,5]. All samples were declared as whole milk (fat content of 3.5-3.6\%), pasteurized and peroxidase positive. For each season of the year 2015: March (Q1), June (Q2), September (Q3) and December (Q4) of 2015, $10 \mathrm{CM}$ and $11 \mathrm{HM}$ samples were acquired and analyzed within their labelled shelf life.

\section{Materials}

For confirming peroxidase activity, a screening ready-touse colorimetric peroxidase test (Merckoquant, Darmstadt, Germany) was used. Following chemicals were used for analysis: ammonia [25\% for analysis], methanol, Methyl tert butyl ether (MTBE), petroleum benzene (boiling range $\left.40-60{ }^{\circ} \mathrm{C}\right), n$-Hexane, potassium hydroxide, sodium sulfate. All chemicals were of analytical grade and obtained from Merck (Darmstadt, Germany).

\section{Fat extraction and sample preparation}

Lipid extraction was performed by an adapted Röse-Gottlieb method [32]. Ten milliliter of milk sample (room temperature, $22{ }^{\circ} \mathrm{C}$ ) were placed in Mojonnier flasks mixed with 
$2 \mathrm{ml}$ of ammonia (25\%) and shaken by hand for some $20 \mathrm{~s}$. In variation to the original Röse-Gottlieb method, $10 \mathrm{ml}$ of ethanol was used instead of methanol in order to avoid the formation of ethyl esters, which would interfere in the chromatogram. To each tube, $25 \mathrm{ml}$ MTBE were added (in variation of Röse-Gottlieb method, instead of diethyl ether for laboratory safety) and strongly shaken for $1 \mathrm{~min}, 25 \mathrm{ml}$ petroleum benzene was added to the extract and shaken for another $30 \mathrm{~s}$, the sample was left for $1 \mathrm{~h}$ to obtain full separation of the layers. After this time, the upper layer was decanted and transferred in to a $100 \mathrm{ml}$ round bottom flask and evaporated to dryness using a rotary evaporator at $40{ }^{\circ} \mathrm{C}$. The extract was re-suspended with $5 \mathrm{ml} n$-Hexane and transferred to a $15 \mathrm{ml}$ glass reaction tube containing a spatulatip of water-free sodium sulfate. For fatty acid methyl ester (FAME) measurement, $2 \mathrm{ml}$ from the upper part of the solution was transferred to a $10 \mathrm{ml}$ glass reaction tube and derivatized with $100 \mu \mathrm{l}$ of $2 \mathrm{~N}$ methanolic potassium hydroxide solution. The sample was shaken for $10 \mathrm{~s}$ and left reacting for another $6 \mathrm{~min}$ [33]. The upper phase was directly used for injection in the GC system. Samples were analyzed within $24 \mathrm{~h}$ after derivatization.

For identification of FAMEs, a SUPELCO 37 component standard was used (Supelco Co., Ltd, Bellefonte, PA, USA). Separation of FAMEs was performed on a gas chromatography system HP 6890 (Agilent, Minnesota, USA) equipped with automatic injector and flame ionization detector. A HP-88 column (100 m length, $0.25 \mathrm{~mm}$ ID) (Agilent, USA) was used at a constant flow rate of $0.6 \mathrm{ml} / \mathrm{min}$ and 1:100 split ratio with nitrogen as carrier gas.

The oven temperature was programmed at an initial setting of $100^{\circ} \mathrm{C}$ and raised after $2 \mathrm{~min}$ at a rate of $15^{\circ} \mathrm{C} / \mathrm{min}$ to $170{ }^{\circ} \mathrm{C}$ followed by a ramp of $1{ }^{\circ} \mathrm{C} / \mathrm{min}$ to a final temperature of $240{ }^{\circ} \mathrm{C}$, which was kept for $6 \mathrm{~min}$. Injector and detector were both set at $250{ }^{\circ} \mathrm{C}$.

\section{GC analysis}

Peak areas were corrected by theoretical response factor described by Schreiner and Hulan [34]. Minor FAs, which eluted after conjugated linoleic acid (CLA), were taken from another GC analysis, which was performed under the same conditions, just by using a splitless injection with a splitless time of $0.5 \mathrm{~min}$. Peak areas of this second chromatogram were related to the peak area of ALA of this chromatogram and related to the peak area of ALA from the first chromatogram, which contained all FAs eluting before CLA. All peak areas were finally normalized to $100 \%$.

\section{Data processing}

Final results were treated by partial least square discriminant analysis (PLS-DA), using the standardized evaluation mode and significance evaluation by two-tailed t-test (confidence interval $\alpha=0.05,0.01$ and 0.001$)$ (Unscrambler ${ }^{\circledR}$, Version 10.2; Camo, Oslo, Norway).

Statistic evaluation was applied in function of two studied factors (kind of milk and season of the year). Registered FAs were expressed in percent (\%) of FAME.

\section{Results and discussion}

A total of 48 FAMEs were registered and quantified. The dominating SFA and MUFA are presented in Table 1. The seasonal differences that were observed are in agreement with existing literature [35]. Comparing the different milk groups, some differences were observed. The major FA in milk, C16:0 differed only in the warm season (Q3) with $30.32 \pm 1.70 \%$ in $\mathrm{CM}$ and $28.96 \pm 1.35 \%$ in $\mathrm{HM}$, whereas for all other seasons no differences were noted. On the other hand, C14:0 and C18:0 showed significant differences between HM and CM in the cold season (Q1 and Q4). An explanation for this behavior of SFA can be seen in the fact that C18:0 in contrast to all the other even chained SFA is not only synthesized de novo in the mammary gland, by the regular FAs metabolism or provided by the diet, but also the final product of bio hydrogenation [22, 26, 36]. Therefore, this result was expected, since any possible differences could only be attributed to crowding-out effects of other FAs, which are affected by feed or microbial activity, which obviously did not occur to a significant extent. Hofstetter et al. [9] and Velik et al. [35] showed lower levels of SFA for raw grass/hay feeding, whereas values for mixed feeding (hay/ concentrated or silage/concentrate) were higher between $63,5 \pm 0.45$ and $68.4 \pm 0.56 \%$ of total FAME.

On the other hand, all odd chain FAs (C11:0, C13:0, C15:0, C17:0 und C23:0), which mainly derive from microbial activity, showed significant differences among the observed groups HM and CM (C19:0 was not evaluated, since a satisfying resolution from other components could not be obtained in a single separation). Especially in this group of FAs some seasonal effects could be observed, which showed a tendency of more significant differences in the cold season (Q1 and Q4). MUFA accounted for approximately $25 \%$ of total FAs (Table 2). They were strongly influenced by season, as shown for oleic acid (C18:1c9) in Fig. 1a, which is also in agreement with published studies [37]. However, there were no differences between feeding groups regarding MUFA when the entire year was observed. Only C14:1 showed differences between HM and CM in Q1 and Q4 and C18:1c9 in Q4, whereas C18:1t differed in the warm season (Q2 and Q3). This later effect was similar to the behavior of odd-chain SFA, which is obviously due to the fact that $\mathrm{C} 18: 1 \mathrm{t}$ is also a product of microbial activity. This seasonal variation of $\mathrm{C} 18: 1 \mathrm{t}$ can be attributed to the 
Table 1 Saturated fatty acids and MUFA percentage in Austrian hay- and conventional milk obtained from Austrian retailers in 2015

\begin{tabular}{|c|c|c|c|c|c|c|c|c|c|}
\hline \multicolumn{2}{|l|}{$\%$ of total FAME } & \multicolumn{8}{|c|}{ Seasonal Variation } \\
\hline \multirow[t]{2}{*}{ SFA and MUFA } & \multirow[t]{2}{*}{$\mathrm{P}^{\mathrm{a}}$} & \multicolumn{2}{|l|}{ Q1 } & \multicolumn{2}{|l|}{ Q2 } & \multicolumn{2}{|l|}{ Q3 } & \multicolumn{2}{|l|}{ Q4 } \\
\hline & & $\mathrm{HM}$ & $\mathrm{CM}$ & $\mathrm{HM}$ & $\mathrm{CM}$ & $\mathrm{HM}$ & $\mathrm{CM}$ & $\mathrm{HM}$ & $\mathrm{CM}$ \\
\hline $\mathrm{C} 4: 0$ & & $3.74 \pm 0.24$ & $3.79 \pm 0.12$ & $3.76 \pm 0.16$ & $3.74 \pm 0.14$ & $3.62 \pm 0.32$ & $3.68 \pm 0.22$ & $4.04 \pm 0.10$ & $4.03 \pm 0.10$ \\
\hline C6:0 & & $2.24 \pm 0.19$ & $2.27 \pm 0.03$ & $2.10 \pm 0.08$ & $2.11 \pm 0.12$ & $2.09 \pm 0.14$ & $2.17 \pm 0.11$ & $2.34 \pm 0.06$ & $2.35 \pm 0.04$ \\
\hline $\mathrm{C} 8: 0$ & & $1.32 \pm 0.11$ & $1.34 \pm 0.04$ & $1.20 \pm 0.10$ & $1.22 \pm 0.10$ & $1.20 \pm 0.09$ & $1.25 \pm 0.07$ & $1.35 \pm 0.08$ & $1.33 \pm 0.03$ \\
\hline C10:0 & & $3.01 \pm 0.27$ & $2.99 \pm 0.15$ & $2.57 \pm 0.13$ & $2.71 \pm 0.17$ & $2.64 \pm 0.18$ & $2.77 \pm 0.19$ & $3.08 \pm 0.19$ & $3.08 \pm 0.11$ \\
\hline C11:0 & $*$ & $0.06 \pm 0.04$ & $0.07 \pm 0.02$ & $0.02 \pm 0.03$ & $0.05 \pm 0.04$ & $0.02 \pm 0.03$ & $0.05 \pm 0.04$ & $0.08 \pm 0.01$ & $0.09 \pm 0.01$ \\
\hline C12:0 & & $3.52 \pm 0.14$ & $3.46 \pm 0.19$ & $3.06 \pm 0.14$ & $3.18 \pm 0.27$ & $3.14 \pm 0.21$ & $3.28 \pm 0.21$ & $3.66 \pm 0.26$ & $3.67 \pm 0.17$ \\
\hline C13:0 & $* *$ & $0.09 \pm 0.03$ & $0.11 \pm 0.01$ & $0.02 \pm 0.02$ & $0.06 \pm 0.02$ & $0.07 \pm 0.06$ & $0.08 \pm 0.04$ & $0.08 \pm 0.01$ & $0.11 \pm 0.01$ \\
\hline C14:0 & & $12.06 \pm 0.66$ & $11.70 \pm 0.19$ & $10.98 \pm 0.62$ & $11.31 \pm 0.63$ & $11.26 \pm 0.38$ & $11.38 \pm 0.43$ & $12.24 \pm 0.12$ & $12.07 \pm 0.09$ \\
\hline C14:1 c9 & $* *$ & $0.97 \pm 0.04$ & $0.88 \pm 0.04$ & $0.77 \pm 0.05$ & $0.77 \pm 0.07$ & $0.87 \pm 0.04$ & $0.87 \pm 0.07$ & $0.95 \pm 0.08$ & $0.87 \pm 0.04$ \\
\hline C15:0 & $* * *$ & $1.32 \pm 0.07$ & $1.26 \pm 0.04$ & $1.21 \pm 0.04$ & $1.17 \pm 0.03$ & $1.24 \pm 0.05$ & $1.19 \pm 0.03$ & $1.27 \pm 0.06$ & $1.22 \pm 0.05$ \\
\hline C16:0 & & $32.41 \pm 1.87$ & $31.82 \pm 0.64$ & $28.28 \pm 1.35$ & $29.66 \pm 2.53$ & $28.96 \pm 1.51$ & $30.32 \pm 1.70$ & $32.74 \pm 2.36$ & $32.58 \pm 0.49$ \\
\hline C16:1 c9 & & $2.10 \pm 0.08$ & $2.06 \pm 0.07$ & $1.91 \pm 0.05$ & $1.98 \pm 0.06$ & $1.89 \pm 0.10$ & $1.98 \pm 0.14$ & $1.95 \pm 0.21$ & $1.84 \pm 0.08$ \\
\hline C17:0 & $* * *$ & $0.67 \pm 0.05$ & $0.60 \pm 0.03$ & $0.65 \pm 0.03$ & $0.61 \pm 0.05$ & $0.65 \pm 0.07$ & $0.61 \pm 0.04$ & $0.64 \pm 0.06$ & $0.56 \pm 0.03$ \\
\hline C18:0 & $*$ & $8.11 \pm 0.76$ & $9.29 \pm 0.31$ & $10.74 \pm 0.38$ & $10.26 \pm 0.94$ & $9.94 \pm 0.41$ & $9.70 \pm 0.70$ & $8.31 \pm 0.58$ & $9.14 \pm 0.28$ \\
\hline $\mathrm{C} 18: 1 \mathrm{t}^{\mathrm{b}}$ & & $2.37 \pm 0.09$ & $2.54 \pm 0.42$ & $3.92 \pm 0.59$ & $3.02 \pm 0.99$ & $4.36 \pm 0.90$ & $3.11 \pm 1.02$ & $2.51 \pm 0.17$ & $2.49 \pm 0.49$ \\
\hline C18:1 c9 & & $17.09 \pm 1.67$ & $17.37 \pm 0.36$ & $20.08 \pm 1.16$ & $19.97 \pm 1.06$ & $18.80 \pm 1.28$ & $18.91 \pm 0.31$ & $15.95 \pm 1.10$ & $17.37 \pm 0.70$ \\
\hline C20:0 & & $0.20 \pm 0.02$ & $0.19 \pm 0.03$ & $0.19 \pm 0.02$ & $0.19 \pm 0.02$ & $0.18 \pm 0.02$ & $0.18 \pm 0.02$ & $0.18 \pm 0.02$ & $0.16 \pm 0.03$ \\
\hline C20:1 c11 & & $0.06 \pm 0.00$ & $0.06 \pm 0.01$ & $0.06 \pm 0.01$ & $0.06 \pm 0.01$ & $0.05 \pm 0.01$ & $0.06 \pm 0.02$ & $0.05 \pm 0.00$ & $0.05 \pm 0.01$ \\
\hline C21:0 & $* * *$ & $0.08 \pm 0.02$ & $0.11 \pm 0.02$ & $0.10 \pm 0.02$ & $0.09 \pm 0.01$ & $0.10 \pm 0.01$ & $0.08 \pm 0.01$ & $0.09 \pm 0.02$ & $0.07 \pm 0.02$ \\
\hline $\mathrm{C} 22: 0$ & $* *$ & $0.09 \pm 0.02$ & $0.08 \pm 0.01$ & $0.08 \pm 0.02$ & $0.08 \pm 0.00$ & $0.08 \pm 0.02$ & $0.08 \pm 0.01$ & $0.08 \pm 0.03$ & $0.06 \pm 0.01$ \\
\hline $\mathrm{C} 22: 1 \mathrm{c} 13$ & & $0.009 \pm 0.00$ & $0.006 \pm 0.00$ & $0.007 \pm 0.00$ & $0.005 \pm 0.00$ & $0.013 \pm 0.01$ & $0.012 \pm 0.01$ & $0.012 \pm 0.01$ & $0.011 \pm 0.01$ \\
\hline C23:0 & $* * *$ & $0.039 \pm 0.01$ & $0.029 \pm 0.01$ & $0.032 \pm 0.01$ & $0.029 \pm 0.01$ & $0.034 \pm 0.01$ & $0.027 \pm 0.01$ & $0.031 \pm 0.01$ & $0.025 \pm 0.01$ \\
\hline $\mathrm{C} 24: 0$ & & $0.03 \pm 0.01$ & $0.02 \pm 0.00$ & $0.02 \pm 0.01$ & $0.02 \pm 0.00$ & $0.03 \pm 0.01$ & $0.02 \pm 0.01$ & $0.02 \pm 0.02$ & $0.02 \pm 0.02$ \\
\hline $\mathrm{C} 24: 1 \mathrm{c} 15$ & & $0.01 \pm 0.02$ & $0.01 \pm 0.00$ & $0.01 \pm 0.01$ & $0.01 \pm 0.00$ & $0.01 \pm 0.01$ & $0.01 \pm 0.01$ & $0.01 \pm 0.03$ & $0.01 \pm 0.01$ \\
\hline
\end{tabular}

Numbers in boldface show significant differences between haymilk (HM) and conventional milk (CM)

Q1 (March), Q2 (June), Q3 (September), Q4 (December) indicate the quarter of sampling

${ }^{a} \mathrm{P}$ significant differences between haymilk and conventional milk in the year $(*<0.05, * *<0.01, * * *<0.001)$

${ }^{\mathrm{b}}$ Total of trans FA

increased content of fresh herbage during summer [38], as shown in Fig. 1a.

Many studies revealed that differences between feeding systems mainly affect PUFA such as ALA and CLA $[3,39]$ which together with linoleic acid (C18:2 c9,12; LA) are the most abundant PUFAs in milk. In average, PUFA in HM were approximately $14 \%$ higher than in CM (Table 2.), although LA was unaffected. Most notably differences were found for ALA in all 4 seasons and CLA in 3 out of 4 seasons between feeding groups. However, there was a different trend in the sense that highest significance for ALA was found in $\mathrm{Q} 1$ and $\mathrm{Q} 4(\mathrm{P}<0.001)$, whereas CLA differed with high significance in $\mathrm{Q} 3(\mathrm{P}<0.001)$ and was also significant in Q4 and Q2 $(\mathrm{P}<0.05)$, but not significant in Q1. This reciprocal trend can be explained by the fact that ALA is entirely deriving from dietary sources and not modified by microbial activity or by the cow's metabolism, whereas the formation of CLA involves microbial bio hydrogenation [19, $23,40]$. Such independent trends can substantially improve the chance to enable statistical discrimination between the groups.

In addition, Table 2 presents a couple of detected minor FAs, which derive from elongation and desaturation of LA and ALA [3]. In essence, these FAs showed the same behavior as their parent FAs. In detail, C18:3c6,9,12, differed between groups in the cold season, C20:2c11,14 showed high seasonal variation, C20:3c8,11,14 and C20:4c5,8,11,14 (arachidonic acid) did not differ between groups, such as their parent FA LA. On the other hand, all omega-3 FAs (C20:3c11,14,17, C20:5c5,8,11,14,17 - EPA and $C 22: 5 \mathrm{c} 7,10,13,16,19$ - DPA) showed differences among feeding groups, like their parent FA ALA. No difference could be observed for DHA, which may be due to the fact that this FA is present at very low amounts. 
Table 2 PUFA composition in Austrian hay- and conventional milk obtained from Austrian retailers in 2015

\begin{tabular}{|c|c|c|c|c|c|c|c|c|c|}
\hline \multicolumn{2}{|l|}{$\%$ of total FAME } & \multicolumn{8}{|c|}{ Seasonal Variation } \\
\hline \multirow[t]{2}{*}{ Polyunsaturated fatty acid } & \multirow[t]{2}{*}{$\mathrm{P}^{\mathrm{a}}$} & \multicolumn{2}{|l|}{ Q1 } & \multicolumn{2}{|l|}{ Q2 } & \multicolumn{2}{|l|}{ Q3 } & \multicolumn{2}{|l|}{ Q4 } \\
\hline & & $\mathrm{HM}$ & $\mathrm{CM}$ & $\mathrm{HM}$ & $\mathrm{CM}$ & $\overline{\mathrm{HM}}$ & $\mathrm{CM}$ & $\overline{\mathrm{HM}}$ & $\mathrm{CM}$ \\
\hline C18:2 c9,12 (LA) & & $1.29 \pm 0.14$ & $1.26 \pm 0.14$ & $1.23 \pm 0.15$ & $1.27 \pm 0.05$ & $1.31 \pm 0.15$ & $1.36 \pm 0.11$ & $1.32 \pm 0.15$ & $1.22 \pm 0.13$ \\
\hline $\mathrm{C} 18: 2 \mathrm{t}$ & & $0.12 \pm 0.06$ & $0.13 \pm 0.07$ & $0.10 \pm 0.06$ & $0.09 \pm 0.08$ & $0.15 \pm 0.07$ & $0.14 \pm 0.09$ & $0.18 \pm 0.05$ & $0.12 \pm 0.06$ \\
\hline C18:2 c9t11 (CLA) & $* *$ & $0.82 \pm 0.09$ & $0.75 \pm 0.22$ & $1.39 \pm 0.22$ & $1.02 \pm 0.36$ & $1.54 \pm 0.30$ & $1.17 \pm 0.40$ & $0.94 \pm 0.16$ & $0.75 \pm 0.13$ \\
\hline C18:3 c9,12,15 (ALA) & $* * *$ & $0.99 \pm 0.13$ & $0.69 \pm 0.13$ & $0.94 \pm 0.09$ & $0.78 \pm 0.19$ & $1.02 \pm 0.13$ & $0.78 \pm 0.18$ & $0.99 \pm 0.16$ & $0.63 \pm 0.15$ \\
\hline C18:3 c6,9,12 & & $0.14 \pm 0.03$ & $0.16 \pm 0.01$ & $0.09 \pm 0.05$ & $0.11 \pm 0.07$ & $0.07 \pm 0.06$ & $0.11 \pm 0.05$ & $0.14 \pm 0.01$ & $0.13 \pm 0.01$ \\
\hline C20:2 c11,14 & $*$ & $0.05 \pm 0.01$ & $0.05 \pm 0.01$ & $0.05 \pm 0.01$ & $0.04 \pm 0.01$ & $0.05 \pm 0.01$ & $0.05 \pm 0.01$ & $0.06 \pm 0.01$ & $0.05 \pm 0.02$ \\
\hline C20:3 c11,14,17 & $* * *$ & $0.02 \pm 0.00$ & $0.01 \pm 0.00$ & $0.02 \pm 0.00$ & $0.01 \pm 0.00$ & $0.02 \pm 0.00$ & $0.01 \pm 0.01$ & $0.02 \pm 0.01$ & $0.01 \pm 0.00$ \\
\hline $\mathrm{C} 20: 3 \mathrm{c} 8,11,14$ & & $0.07 \pm 0.01$ & $0.07 \pm 0.01$ & $0.06 \pm 0.01$ & $0.07 \pm 0.01$ & $0.08 \pm 0.01$ & $0.07 \pm 0.01$ & $0.06 \pm 0.01$ & $0.06 \pm 0.02$ \\
\hline C20:4 c5,8,11,14 & & $0.10 \pm 0.03$ & $0.09 \pm 0.02$ & $0.09 \pm 0.02$ & $0.09 \pm 0.02$ & $0.09 \pm 0.02$ & $0.09 \pm 0.03$ & $0.09 \pm 0.03$ & $0.09 \pm 0.02$ \\
\hline C20:5 c5,8,11,14,17 (EPA) & $* * *$ & $0.10 \pm 0.01$ & $0.07 \pm 0.02$ & $0.09 \pm 0.02$ & $0.08 \pm 0.01$ & $0.09 \pm 0.01$ & $0.07 \pm 0.01$ & $0.09 \pm 0.03$ & $0.06 \pm 0.01$ \\
\hline $\mathrm{C} 22: 5$ c $7,10,13,16,19$ (DPA) & $* *$ & $0.07 \pm 0.03$ & $0.07 \pm 0.02$ & $0.08 \pm 0.02$ & $0.07 \pm 0.01$ & $0.09 \pm 0.03$ & $0.06 \pm 0.03$ & $0.08 \pm 0.03$ & $0.06 \pm 0.03$ \\
\hline C22:6 c4,7,13,16,19 (DHA) & & $0.01 \pm 0.02$ & $0.01 \pm 0.01$ & $0.01 \pm 0.03$ & $0.01 \pm 0.00$ & $0.01 \pm 0.03$ & $0.01 \pm 0.02$ & $0.01 \pm 0.02$ & $0.01 \pm 0.02$ \\
\hline
\end{tabular}

Numbers in boldface show significant differences between haymilk (HM) and conventional milk (CM)

Q1 (March), Q2 (June), Q3 (September), Q4 (December) indicate the quarter of sampling

$\mathrm{P}^{\mathrm{a}}$ significant differences between haymilk and conventional milk in the year $(*<0.05, * *<0.01, * * *<0.001)$

Figure $1 \mathrm{~b}$ presents seasonal variations of CLA and ALA. Whereas the levels of ALA in HM as well as in CM and also the difference between these two levels remained more or less constant over the year, the concentration of CLA and especially the difference between the two feed regimes was markedly increased during Q2 and Q3. The marked influence of the seasons will consequently weaken the statistical strength, when only one single data set is established for all seasons.

While all these differences are well explained and reproducible in feeding trials under controlled conditions, differentiation between HM and CM in retail milk is more complicated for two reasons: First, consumer milk is a mixture from multiple individual animals, delivered from several producers, so that single feeding effects are likely to be obscured.

\section{Data evaluation by multivariate statistics}

Strong seasonal variation of many relevant FAs suggested that data treatment by multivariate statistics might be a promising approach to discriminate between feeding regimens. It has been shown in a previous paper that PLS-DA is producing more suitable results in this specific problem than Principal Component Analysis, because the study group classification is considered for the calculation of the principal components in order to gain a better prediction for unknown samples [31].

The correlation loadings (Figs. 2, 3) of FAs, confirm the data shown in Tables 1 and 2 in the sense that ALA, and its elongation and desaturation metabolites (C20:3c11,14,17 and EPA), as well as CLA are most responsible for discrimination of the groups together with bacterial (odd chain and trans) FAs. These FAs were also the only ones that contributed to discrimination of the feeding groups in all seasons, which is in accordance with the findings of Bloksma et al. [41], who found higher contents of CLA in organic milk. The reason for this behavior can be that CLA is a product of feed-derived FA (usually ALA) and additional modification by bacterial activity.

The grouping for $\mathrm{HM}$ and $\mathrm{CM}$ of samples collected in warm period (Q2 and Q3) was evident, the discrimination of the feeding groups was achieved for most, but not all single samples (Fig. 4a), as observed by comparison of Fig. 4b. Four CM samples - 7,8,17,18-were from alpine regions and commercialized as conventional milk and contained similarly high values of CLA as HM. Better separation was obtained for the cold period (Q1 and Q4), where a clear grouping was observed (Fig. 4b).

\section{Conclusion}

In the present study, it was shown that PLS-DA is a suitable method for discriminating HM and CM from commercial samples. Furthermore, it was shown that in warm period (fresh grass access), differences are still discriminable between CM and HM, but diminished. This result is due to the fact, that in this time the feeding regime for the production of CM is nearly the same as for HM. Therefore, an approach that uses different calibrations in summer 

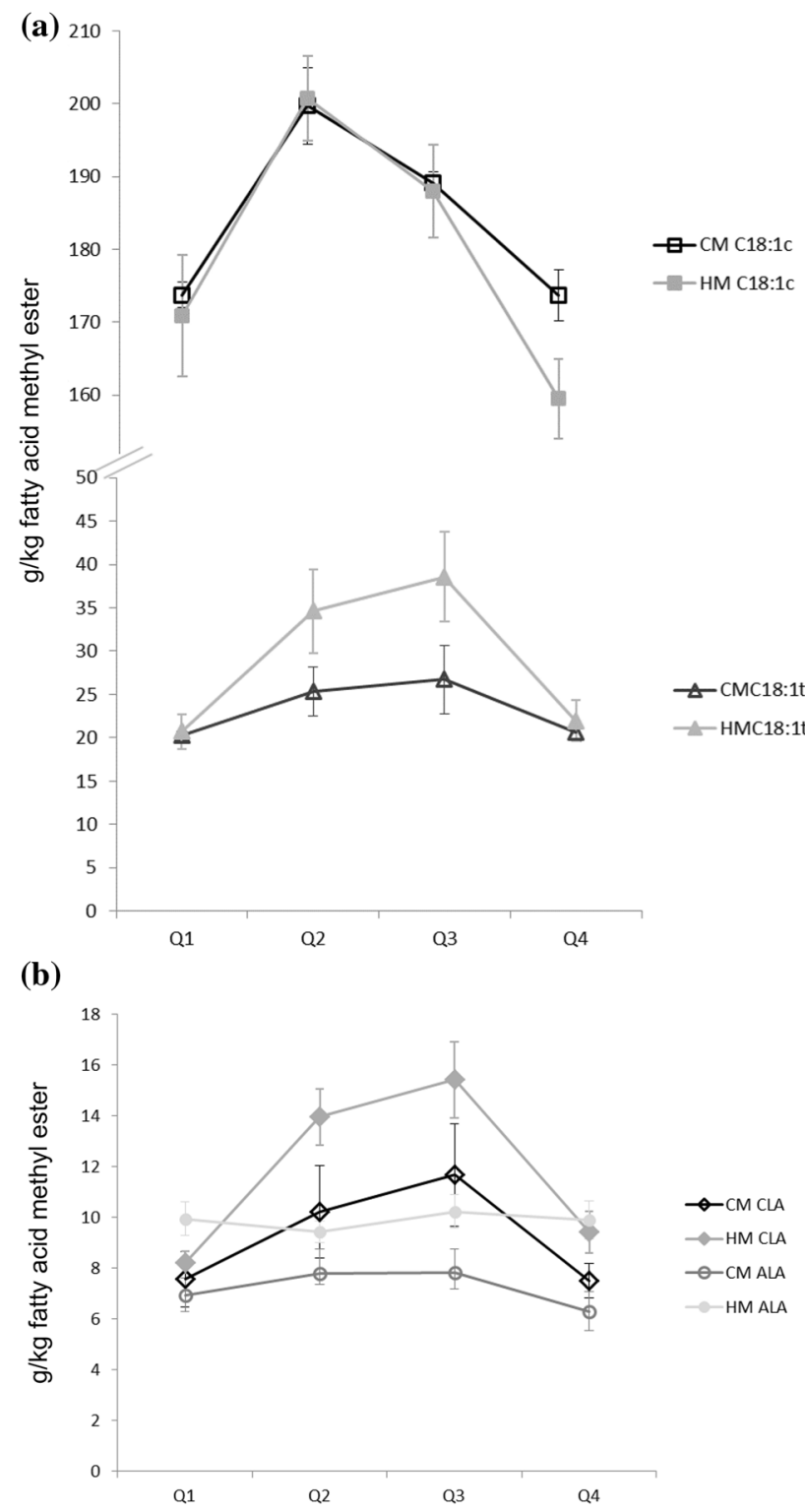

Fig. 1 a Monounsaturated fatty acid (C18:1) expressed in $\mathrm{g} / \mathrm{kg}$ fatty acid methyl ester in the different quarters of year (month of sampling). $C M$ conventional milk, $H M$ haymilk, $Q 1$ March, $Q 2$ June, $Q 3$ September, $Q 4$ December. b Polyunsaturated fatty acids expressed in $\mathrm{g} / \mathrm{kg}$ fatty acid methyl ester in the different quarters of year (month of sampling). $C M$ conventional milk, $H M$ haymilk, $Q 1$ March, $Q 2$ June, Q3 September, $Q 4$ December

and winter is necessary. The winter calibration should be performed as described above. For the summer season, we suggest a monovariate differentiation by the level of

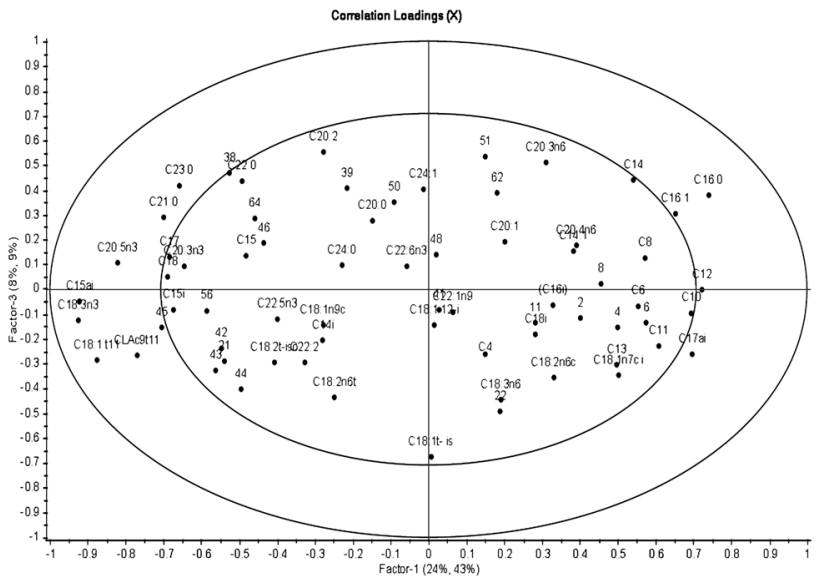

Fig. 2 Result of PLS-DA with standardized variables in warm period, Q2 quarter 2 (June), Q3 quarter 3 (September), correlations loadings for factors 1 and 3 . Labels indicate peak names

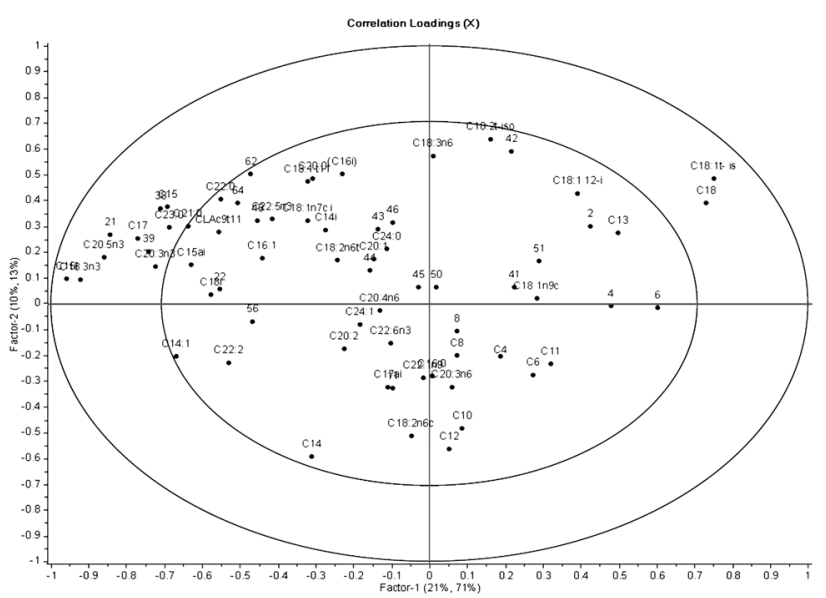

Fig. 3 Result of PLS-DA with standardized variables in cold period. Q1 quarter 1 (March), Q4 quarter 4 (December). Correlations loadings for factors 1 and 2. Labels indicate peak names

ALA, which showed significant differences throughout the season.

The aim of the study to implement FA spectra to match HM quality with samples declared as "Heumilch" in food labelling was completely achieved, also for the GC-FID based method used here. For future research, study on longterm variations of FA profiles over a couple of years should be foreseen. 
(a)

Predicted with Deviation

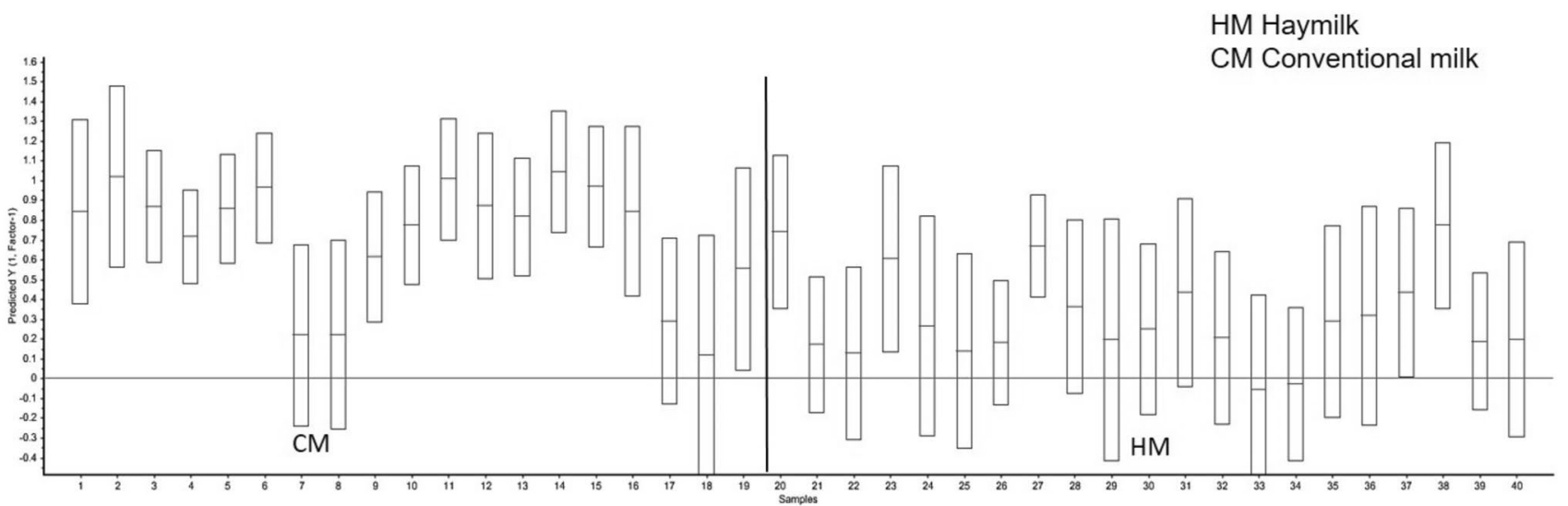

(b)

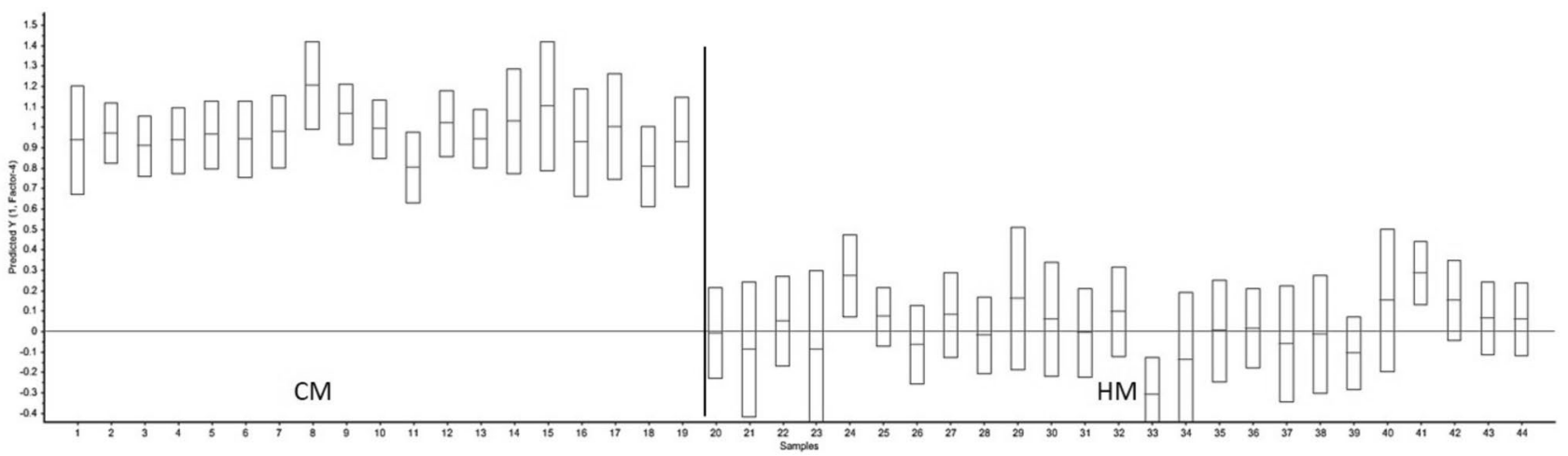

Fig. 4 a Predicted values estimated deviation of prediction (rectangle) according to the PLS-DA [warm period, $Q 2$ quarter 2 (June), $Q 3$ quarter 3 (September)]. $C M$ conventional milk, $H M$ haymilk. Labels indicate the labeling of samples. b Predicted values estimated devia- tion of prediction (rectangle) according to the PLS-DA [cold period, Q1 quarter 1 (March), Q4 quarter 4 (December)]. CM conventional milk, $H M$ haymilk. Labels indicate the labeling of samples

3. P. Kalač, E. Samková, The effects of feeding various forages on fatty acid composition of bovine milk fat: A review. Czech J. Anim. Sci. 55, 521-537 (2010)

4. A.R.G.E. Heumilch, Heumilch. ARGE Heumilch, http://www. heumilch.at/heumilch/die-arge-heumilch/. Accessed 2 May 2017, (2017)

5. The European Parliament and the Council of the European Union, Regulation (EU) no 1151/2012 of the European Parliament and of the Council of 21 November 2012 on quality schemes for agricultural products and foodstuffs. Off. J. Eur. Union. L 343, 1-28 (2012)

6. C. Bugaud, S. Buchin, J. Coulon, A. Hauwuy, D. Dupont, Influence of the nature of alpine pastures on plasmin activity, fatty acid and volatile compound composition of milk. Lait. 81, 401-414 (2001)

7. G. Roda, S. Fialà, M. Vittorini, F. Secundo, Fatty acid composition and fat content in milk from cows grazing in the Alpine region. Eur. Food Res. Technol. 241, 413-418 (2015)

8. O.M. Harstad, H. Steinshamn, Cow's diet and milk composition, in Improving the Safety and Quality of Milk, vol. 1, ed. by M. W. Griffiths (Woohead Publishing Limited, Neuware, 2010), pp. 223-245 
9. P. Hofstetter, H.J. Frey, C. Gazzarin, U. Wyss, P. Kunz, Dairy farming: indoor v. pasture-based feeding. J. Agric. Sci. 152, 994-1011 (2014)

10. A. AbuGhazaleh, L. Holmes, Altering dairy cows milk fatty acid composition through grazing and oil supplementation. Milchwissenschaft. 3, 241-244 (2009)

11. P. Moate, S. Williams, M. Hannah, R. Eckard, M. Auldist, B. Ribaux, J. Jacobs, W. Wales, Effects of feeding algal meal high in docosahexaenoic acid on feed intake, milk production, and methane emissions in dairy cows. J. Dairy Sci. 96, 3177-3188 (2013)

12. P. Póti, F. Pajor, Á Bodnár, K. Penksza, P. Köles, Effect of microalga supplementation on goat and cow milk fatty acid composition. Chil. J. Agric. Res. 75, 259-263 (2015)

13. F. Bargo, J. Delahoy, G. Schroeder, L. Muller, Milk fatty acid composition of dairy cows grazing at two pasture allowances and supplemented with different levels and sources of concentrate. Anim. Feed Sci. Technol. 125, 17-31 (2006)

14. L. Bernard, C. Leroux, J. Rouel, C. Delavaud, K. Shingfield, Y. Chilliard, Effect of extruded linseeds alone or in combination with fish oil on intake, milk production, plasma metabolite concentrations and milk fatty acid composition in lactating goats. Animal. 9, 810-821 (2015)

15. T.R. Dhiman, G.R. Anand, L.D. Satter, M.W. Pariza, Conjugated linoleic acid content of milk from cows fed different diets. J. Dairy Sci. 82, 2146-2156 (1999)

16. M. Villeneuve, Y. Lebeuf, R. Gervais, G. Tremblay, J. Vuillemard, J. Fortin, P. Chouinard, Milk volatile organic compounds and fatty acid profile in cows fed timothy as hay, pasture, or silage. J. Dairy Sci. 96, 7181-7194 (2013)

17. M. Mele, A. Serra, A. Buccioni, G. Conte, A. Pollicardo, P. Secchiari, D. Contenenti, D. Rapporti, F. Concentrato, Effect of soybean oil supplementation on milk fatty acid composition from Saanen goats fed diets with different forage: concentrate ratios. Italy J. Anim. Sci. 7, 297-311 (2008)

18. M. Eastridge, P. Bucci, C. Ribeiro, Feeding equivalent concentrations of forage neutral detergent fiber from alfalfa hay, grass hay, wheat straw, and whole cottonseed in corn silage based diets to lactating cows. Anim. Feed Sci. Technol. 150, 86-94 (2009)

19. R. Grummer, Effect of Feed on the Composition of Milk Fat. J. Dairy Sci. 74, 3244-3257 (1991)

20. L. Bernard, M. Bonnet, C. Leroux, K.J. Shingfield, Y. Chilliard, Effect of sunflower-seed oil and linseed oil on tissue lipid metabolism, gene expression, and milk fatty acid secretion in Alpine goats fed maize silage-based diets. J. Dairy Sci. 92, 6083-6094 (2009)

21. L. Bernard, K.J. Shingfield, J. Rouel, A. Ferlay, Y. Chilliard, Effect of plant oils in the diet on performance and milk fatty acid composition in goats fed diets based on grass hay or maize silage. Br. J. Nutr. 101, 213-224 (2009)

22. M. Coppa, A. Gorlier, M. Lonati, B. Martin, E.M. Russo, G. Lombardi, The management of the transition from hay- to pasturebased diets affects milk fatty acid kinetics. Dairy Sci. Technol. 92, 279-295 (2012)

23. E. Staszak, Conjugated linoleic acid (CLA) content of milk from cows fed different diets. Folia Biol. (Praha). 53, 103-106 (2005)

24. G. Akbaridoust, T. Plozza, V. Trenerry, W. Wales, M. Auldist, F. Dunshea, S. Ajlouni, Influence of different systems for feeding supplements to grazing dairy cows on milk fatty acid composition. J. Dairy Res. 81, 156-163 (2014)

25. J. Molkentin, Authentication of organic milk using $\delta 13 \mathrm{C}$ and the $\alpha$-linolenic acid content of milk fat. J. Agric. Food Chem. 57, 785-790 (2009)
26. D. Bernardini, G. Gerardi, C.A. Elia, G. Marchesini, S. Tenti, S. Segato, Relationship between milk fatty acid composition and dietary roughage source in dairy cows. Vet. Res. Commun. 34(1), 135-138 (2010)

27. M. van Zyl, R. Meeske, G. Scholtz, O. Einkamerer, The effect of lucerne (Medicago Sativa) hay quality on milk production and composition of Jersey cows. S. Afr. J. Anim. Sci. 44, S25-S30 (2014)

28. F.E. Contreras-Govea, R.E. Muck, P.J. Weimer, and U.C. HymesFecht, In vitro ruminal fermentation of treated alfalfa silage using ruminal inocula from high and low feed-efficient lactating cows. J. Appl. Microbiol. 121, 333-340 (2016)

29. A. Caligiani, A. Marseglia, G. Palla, An overview on the presence of cyclopropane fatty acids in milk and dairy products. J. Agric. Food Chem. 62, 7828-7832 (2014)

30. K.A. Omar, M.E. Gounga, R. Liu, W. Mwinyi, W. Aboshora, A.H. Ramadhan, K.A. Sheha, X. Wang, Triacylglycerol composition, melting and crystallization profiles lipase catalyzed hydrolysis of anhydrous milk fats. Int. J. Food Prop. (2017). https://doi. org/10.1080/10942912.2017.1301954

31. M. Werteker, S. Huber, S. Kuchling, B. Rossmann, M. Schreiner, Differentiation of milk by fatty acid spectra and principal component analysis. Measurement. 98, 311-320 (2017)

32. Verband Deutscher Landwirtschaftlicher Untersuchungs- und Forschungsanstalten (VDLUFA), Bestimmung des Fettgehaltes von Milch und Milchprodukten: Verfahren nach RÖSE-GOTTLIEB. in VDLUFA Methodenbuch, edited by Verband Deutscher Landwirtschaftlicher Untersuchungs- und Forschungsanstalten, p. (VDLUFA, Darmstadt, 1985) C 15.2.1

33. S.W. Christopherson, R. Glass, Preparation of milk fat methyl esters by alcoholysis in an essentially nonalcoholic solution. J. Dairy Sci. 52, 1289-1290 (1969)

34. M. Schreiner, H. Hulan, Determination of the carbon deficiency in the flame ionization detector response of long-chain fatty acid methyl esters and dicarboxylic acid dimethyl esters. J. Chromatogr. A. 1045, 197-202 (2004)

35. M. Velik, S. Breitfuss, M. Urdl, J. Kaufmann, A. Steinwidder, Fettsäurenmuster von Alm- Vollweide- und Supermarkt-Milch sowie von Milch aus Heu- bzw. Maissilage-Ration. Züchtungskunde. 86, 237-248 (2014)

36. B. Vlaeminck, V. Fievez, A. Cabrita, A. Fonseca, R. Dewhurst, Factors affecting odd- and branched-chain fatty acids in milk: a review. Anim. Feed Sci. Technol. 131, 389-417 (2006)

37. H. Lindmark, Månsson, Fatty acids in bovine milk fat. Food Nutr. Res. 52, 1-3 (2008)

38. M. Coppa, A. Ferlay, C. Chassaing, C. Agabriel, F. Glasser, Y. Chilliard, G. Borreani, R. Barcarolo, T. Baars, D. Kusche, O. Harstad, J. Verbič, J. Golecký, B. Martin, Prediction of bulk milk fatty acid composition based on farming practices collected through on-farm surveys. J. Dairy Sci. 96, 4197-4211 (2013)

39. A. Romanzin, M. Corazzin, E. Piasentier, S. Bovolenta, Effect of rearing system (mountain pasture vs. indoor) of Simmental cows on milk composition and Montasio cheese characteristics. J. Dairy Res. 80, 390-399 (2013)

40. A. Töpel, Lipide - Milchfett. in Chemie und Physik der Milch, (B. Behr's Verlag GmbH \& Co., Hamburg, 2007), pp. 133-147

41. J. Bloksma, R. Adriaansen-Tennekes, M. Huber, L. Van de Vijver, T. Baars, J. De Wit, Comparison of organic and conventional raw milk quality in The Netherlands. Biol. Agric. Hortic. 26, 69-83 (2008) 